\title{
High incidence of high-risk HPV in benign and malignant lesions of the larynx
}

\author{
ANAËLLE DURAY ${ }^{1}$, GÉRALDINE DESCAMPS ${ }^{1}$, MOHAMMAD ARAFA $^{2}$, CHRISTINE DECAESTECKER $^{3}$, \\ MYRIAM REMMELINK ${ }^{4}$, NICOLAS SIRTAINE ${ }^{5}$, PERLE ERNOUX-NEUFCOEUR ${ }^{1}$, EUGÈNE MUTIJIMA ${ }^{2}$, \\ JOAN SOMJA ${ }^{2}$, CHRISTOPHE E. DEPUYDT ${ }^{7}$, PHILIPPE DELVENNE ${ }^{2}$ and SVEN SAUSSEZ ${ }^{1.6}$ \\ ${ }^{1}$ Laboratory of Anatomy, Faculty of Medicine and Pharmacy, University of Mons, Mons; \\ ${ }^{2}$ Department of Pathology, CHU Sart-Tilman, University of Liège, Liège; ${ }^{3}$ Laboratory of Toxicology, \\ Institute of Pharmacy, ${ }^{4}$ Department of Pathology, Hôpital Erasme, ${ }^{5}$ Department of Pathology, \\ Faculty of Medicine, Institut Bordet, ${ }^{6}$ Department of Oto-Rhino-Laryngology, CHU Saint-Pierre, \\ Université Libre de Bruxelles, Brussels; ${ }^{7}$ Laboratory for Clinical Pathology and \\ Molecular Biology (Labo Lokeren, campus Riatol), Antwerp, Belgium
}

Received December 1, 2010; Accepted January 14, 2011

DOI: $10.3892 /$ ijo.2011.1031

\begin{abstract}
The aim of this study was to determine the prevalence of human papillomavirus (HPV) in patients with laryngeal benign lesions (LBLs) and laryngeal squamous cell carcinomas (LSCCs) using a sensitive E6/E7 type-specific PCR. Paraffinembedded samples from LBL $(n=39)$ and LSCC patients $(n=67)$ were evaluated for the presence of HPV DNA by $\mathrm{GP}^{+} / \mathrm{GP}^{+}$ consensus PCR and E6/E7 type-specific PCR for HPV types $6,11,16,18,31,33,35,39,45,51,52,53,56,58,59,66$ and 68. In LSCCs, immunohistochemical staining of p16, p53 and EGFR was also assessed. The E6/E7 type-specific PCR showed that 44 out of 59 LSCC patients (i.e., 75\%) had high-risk (hr) HPV types and that 27 out of $35 \mathrm{LBL}$ patients (i.e., 77\%) had hrHPV types. HPV-16 viral load was significantly higher in LSCC than in LBL patients $\left(\mathrm{p}<10^{-6}\right)$. The presence of hrHPV DNA did not correlate with the proportion of disease-free patients. Comparable levels of p16, p53 and EGFR expression were observed in the hrHPV ${ }^{+}$tumor group $\left(100 \% \mathrm{p} 16^{+}, 56 \% \mathrm{p} 53^{+}\right.$and $\left.97 \% \mathrm{EGFR}^{+}\right)$and in the $\mathrm{HPV}^{-}$or low-risk (lr) $\mathrm{HPV}^{+}$tumor group $\left(92 \% \mathrm{p} 16^{+}, 66 \%\right.$ $\mathrm{p} 53^{+}$and $100 \% \mathrm{EGFR}^{+}$). A very high prevalence of oncogenic HPV-16 was found in a series of benign and malignant laryngeal lesions. LSCC appears to be characterized by an active hrHPV infection. In LSCCs, the hrHPV ${ }^{+}$subgroup had a similar prognosis (in terms of risk of recurrence) as the $\mathrm{HPV}^{-}$subgroup.
\end{abstract}

Correspondence to: Dr S. Saussez, Laboratory of Anatomy, Faculty of Medicine and Pharmacy, University of Mons, Pentagone 2A-Avenue du Champ de Mars 6, B-7000 Mons, Belgium

E-mail: sven.saussez@umons.ac.be

Key words: human papillomavirus, PCR, typing, larynx, benign, carcinoma

\section{Introduction}

Head and neck squamous cell carcinomas (HNSCCs) are characterized by varying rates of incidence and mortality around the world, such as higher rates in Southeast Asia and Eastern Europe (1). Besides being associated with well-established risk factors, such as smoking and alcohol use, the development of laryngeal carcinoma (LSCC) has also been reported to be associated with some human papillomaviruses (HPVs) (2). Nearly 30 years ago, Gissman and colleagues detected the DNA sequences of HPV-6 and -11 in genital and laryngeal papillomas (3). Laryngeal papillomatosis is the most prevalent benign tumor of the larynx in children, and mother-to-child transmission is probably involved in juvenile-onset papillomatosis (2). Several of the 120 HPV genotypes have been detected in LSCCs, and the prevalence of HPV has been estimated to range between 3-85\% (2,4-10). Although the most important clinical manifestation of laryngeal HPV infection is laryngeal papillomatosis (HPV incidence: $83-100 \%)$, HPV DNA is also detected in normal mucosa (incidence: $20 \%$ ) and in LSCCs (2). Indeed, Nunez et al (11) showed that post-mortem specimens of macroscopically normal laryngeal mucosa and hypopharyngeal mucosa were $\mathrm{HPV}^{+}$in 25 and $18 \%$ of cases, respectively.

In laryngeal papilloma lesions, HPV-6 and HPV-11 are the most commonly encountered types, whereas HPV-16 is the most frequently detected type in laryngeal carcinomas. Recently, Mammas and co-authors showed that other HPVs such as HPV-13, 39, 40 and 56 were detected in recurrent respiratory papillomatosis (12). The course of adult-onset laryngeal papillomatosis remains unpredictable, but several studies have reported that HPV DNA is detectable both in biopsy specimens from uninvolved sites and from patients in remission (13). Malignant transformation of laryngeal papillomas is a rare event that occurs in only 3-7\% of patients. Smoking and low-risk (lr) or high-risk (hr) HPV infections have been proposed to be cofactors in the conversion of laryngeal papillomas into carcinomas (14). 
Studies on the mucosal oncogenic types of HPV have demonstrated that the products of two early genes, the E6 and E7 oncoproteins, play crucial roles in malignant transformation (15). The E6 oncoprotein promotes the degradation of p53 via the ubiquitin pathway (16). The E7 oncoprotein has a strong affinity for $\mathrm{pRb}$ and promotes its degradation $(5,17,18)$. The E5 oncoprotein has been suggested to play a role in the early stimulation of growth of HPV-infected cells via an interaction with EGFR (17,19).

The aim of this study was to assess the presence of HPV DNA (by GP5 ${ }^{+} / \mathrm{GP}^{+}$consensus PCR and subsequent genotyping using E6/E7 type-specific PCR for 18 HPV types) in a series of 39 laryngeal benign lesions (LBLs) and 67 laryngeal squamous cell carcinomas (LSCCs) (stages I, II and IV) that were characterized during a long-term follow-up. Moreover, we examined the expression patterns of p16, p53 and EGFR and their correlation with the presence of HPV DNA to predict the survival of LSCC patients.

\section{Materials and methods}

Histopathological and clinical data. Formalin-fixed, paraffinembedded laryngeal squamous cell carcinoma (LSCC) specimens were obtained from 67 patients who underwent radical curative surgery between January 2001 and December 2007 at the Saint-Pieter Hospital (Brussels, Belgium). For each surgical specimen, we selected the paraffin block that presented the highest proportion of carcinoma and avoided the necrotic area frequently observed in the central part of the tumor. Clinical staging was performed according to the TNM classification system (20), and the data describing the tumors of the 67 LSCC patients are detailed in Table I. The diagnoses were based on the histological criteria previously described by Hyams et al (21). All laryngeal SCCs included in this study were primary tumors, and the patients did not have any distant metastases or recurrences. This retrospective study was approved by the local Institutional Review Board. All of the LSCC specimens used in this study came from patients who did not undergo chemotherapy and/or radiotherapy before surgery. Our clinical series of laryngeal SCC specimens represented a clinically and histopathologically homogeneous sample. The series of 39 LBLs was composed of 20 vocal nodules, 6 papillomas and 13 chronic laryngitis; the 39 LBLs are described in Table II.

DNA extraction. The formalin-fixed, paraffin-embedded tissue samples $(\mathrm{n}=106)$ were sectioned $(10 \times 5 \mu \mathrm{m})$, deparaffinized, digested with proteinase $\mathrm{K}$ and incubated overnight at $56^{\circ} \mathrm{C}$. DNA was purified using the QIAamp DNA Mini Kit (Qiagen, Benelux, Belgium) according to the manufacturer's recommended protocol.

Detection of HPV by polymerase chain reaction (PCR) amplification. HPV detection was performed by PCR using the $\mathrm{GP}^{+} / \mathrm{GP}^{+}$primers (synthesized by Eurogentec, Liege, Belgium). The $\mathrm{GP}^{+} / \mathrm{GP}^{+}$primers amplify a conserved sequence located within the L1 region of the HPV genome. The PCR amplification of the HPV-L1 DNA was performed in a $25-\mu \mathrm{l}$ reaction that consisted of $2 \mu \mathrm{l}$ of extracted DNA, $2.5 \mu \mathrm{l} 1 \mathrm{X}$ PCR buffer, 0.025 U Taq DNA polymerase (Roche, Mannheim,
Germany), $200 \mu \mathrm{M}$ dNTPs and 0.5 pmol of each primer. The cycling conditions for PCR were as follows: denaturation was performed at $94^{\circ} \mathrm{C}$ for $1 \mathrm{~min}$, annealing was performed at $55^{\circ} \mathrm{C}$ for $90 \mathrm{sec}$, and extension was performed at $72^{\circ} \mathrm{C}$ for $2 \mathrm{~min}$ for a total of 45 amplification cycles. The first cycle was preceded by a 7 -min denaturation step at $94^{\circ} \mathrm{C}$, and the last cycle was followed by an additional 10-min extension step at $72^{\circ} \mathrm{C}$. Aliquots $(10 \mu \mathrm{l})$ of each PCR product were electrophoresed on a $1.8 \%$ agarose gel and stained with ethidium bromide to visualize the amplified HPV-L1 DNA fragments.

Real-time quantitative PCR amplification of HPV typespecific DNA. All DNA extracts were tested for the presence of 18 different HPV genotypes using TaqMan-based real-time quantitative PCR that targeted type-specific sequences of the following viral genes: type $6 \mathrm{E} 6$, type $11 \mathrm{E} 6$, type $16 \mathrm{E} 7$, type 18 E7, type 31 E6, type 33 E6, type 35 E6, type 39 E7, type $45 \mathrm{E} 7$, type $51 \mathrm{E} 6$, type $52 \mathrm{E} 7$, type $53 \mathrm{E} 6$, type $56 \mathrm{E} 7$, type $58 \mathrm{E} 6$, type $59 \mathrm{E} 7$, type $66 \mathrm{E} 6$, type $67 \mathrm{~L} 1$ and type $68 \mathrm{E} 7$ (22). For the different real-time quantitative PCR assays, the analytical sensitivity ranged from 1-100 copies and was calculated using standard curves generated with plasmids containing the entire genome of the different HPV types (21). Real-time quantitative PCR of $\beta$-globin was performed for each sample to verify the quality of DNA and to measure the amount of input DNA $(23,24)$. The following HPV types were considered to be high risk (hr): 16, 18, 31, 33, 35, 39, 45, 51, $52,53,56,58,59$ and 66.

Immunohistochemistry. All tumor samples were fixed in $4 \%$ buffered formaldehyde for $24 \mathrm{~h}$, dehydrated and embedded in paraffin. Immunohistochemistry was performed on 5- $\mu \mathrm{m}$ thick sections mounted on silane-coated glass slides (25). Before starting the immunohistochemistry protocol, deparaffinized tissue sections were placed in a $0.01 \mathrm{M}$ citrate buffer ( $\mathrm{pH}$ 6.0) and briefly pre-treated in a $900-\mathrm{W}$ microwave for $2 \times 5 \mathrm{~min}$. The sections were then incubated in a solution of $0.06 \%$ hydrogen peroxide for $5 \mathrm{~min}$ to block endogenous peroxidase activity, rinsed in phosphate-buffered saline (PBS; $0.04 \mathrm{M} \mathrm{Na}_{2} \mathrm{HPO}_{4}$, $0.01 \mathrm{M} \mathrm{KH}_{2} \mathrm{PO}_{4}$ and $0.12 \mathrm{M} \mathrm{NaCl}, \mathrm{pH} 7.4$ ) and successively exposed to solutions containing avidin $(0.1 \mathrm{mg} / \mathrm{ml}$ in PBS) and biotin $(0.1 \mathrm{mg} / \mathrm{ml}$ in PBS) for 5 min each to prevent false-positive staining reactions from the presence of endogenous biotin. After thorough washing with PBS, the sections were incubated for $15 \mathrm{~min}$ in a solution of $0.5 \%$ casein in PBS and sequentially exposed to the following solutions at room temperature: i) the specific primary antibody, ii) the corresponding biotinylated secondary antibody (polyclonal goat anti-rabbit $\mathrm{IgG}$ ) and iii) the avidin-biotin-peroxidase complex (ABC) kit. The samples were subjected to thorough washing between incubation steps to remove unbound proteins. The antigen-dependent presence of the peroxidase complex in the sections was visualized by incubation with the chromogenic substrates diaminobenzidine and $\mathrm{H}_{2} \mathrm{O}_{2}$. After rinsing, the sections were counterstained with luxol fast blue and mounted in synthetic medium. To exclude antigen-independent staining, the incubation steps with primary/secondary antibodies were omitted from the protocol in control samples. In all instances, these controls were negative. The biotinylated secondary antibodies and $\mathrm{ABC}$ kit were obtained from DakoCytomation 
Table I. Clinical data.

\begin{tabular}{ccc}
\hline Variable & Low-stage & High-stage \\
LSCCs & LSCCs \\
Stages I \& II & Stage IV \\
46 cases & 21 cases \\
\hline
\end{tabular}

Age (years)

Range

Average

36-88

43-78

Sex (cases)

Male

Female

Site (cases)

Supraglottic area

Glottic area

Supraglottic and glottic areas

Subglottic and glottic areas

Histological grade (cases)

Well differentiated

Moderately differentiated

Poorly differentiated

TNM stage (cases)

T1N0M0

T2N0M0

T4NOM0

T4N1M0

T4N2M0

Tumor treatment (cases)

$\mathrm{Co}_{2}$ laser cordectomy

Frontolateral laryngectomy

Vertical partial laryngectomy

Supracricoid partial laryngectomy

Supraglottic laryngectomy

Total laryngectomy

Treatment of the neck (cases)

Functional neck dissection

Radical neck dissection

Histology (cases)

Positive margins

Larynx cartilage invasion

Positive node/capsular effraction

Recurrence (cases)

Local recurrence

Nodal recurrence

Distant recurrence

Follow-up

Range (months)

Average (months)
Table II. Clinical data.

Clinical data of patients with laryngeal benign lesions

\section{Diagnosis}

Vocal nodule

20 cases

Chronic laryngitis

13 cases

Papilloma

6 cases

Age (years)

Range

Average

Sex (cases)

Male

23

Female

(Glostrup, Denmark). The p16, p53 and EGFR antibodies were purchased, respectively, from Abcam (Cambridge, UK), DakoCytomation and Invitrogen (Camarillo, CA, USA). Assessments of p16, p53 and EGFR immunoreactivities were performed by two independent investigators who were blind to the clinical details of the patients. Tumors were classified in a binary manner as either p16, p53 and EGFR-positive (strong, diffuse staining) or p16, p53 and EGFR-negative (weak or absent staining; i.e., the labeling index (LI) corresponding to the percentage of immunopositive cells was $\leq 5 \%$ ).

Data analysis. Categorical data from the independent groups were compared using the $\chi^{2}$ test or Fisher's exact test, as deemed appropriate. Survival was measured in months from the date of diagnosis until death or until the date at which the patient was last known to be alive. The standard survival time analyses were performed using Kaplan-Meier curves and Gehan's generalized Wilcoxon's and log-rank tests. The statistical analyses were performed using the Statistica software package (Statsoft, Tulsa, OK, USA).

\section{Results}

HPV status in benign laryngeal lesions. Four out of 39 specimens had insufficient tissue quantities for DNA extraction after pathological evaluation and were therefore excluded from further analyses (Fig. 1). In the 35 remaining specimens, $\beta$-globin was positively amplified. In our series of 35 benign laryngeal lesion samples, we identified 27 lesions (77\%) that were positive for hrHPVs. All of these specimens were positive for HPV-16. Moreover, multiple HPV types were detected in four lesions (i.e., one case was also positive for HPV-51 and three cases were infected with lrHPV types 6 or 11). In the hrHPV-negative subgroup $(n=8)$, two specimens tested positive for $\mathrm{HPV}$ using the $\mathrm{GP}^{+} / \mathrm{GP}^{+}$consensus primers and were considered to be infected with lrHPV types (Fig. 1). Only six benign lesions were negative in both $\mathrm{GP}^{+} / \mathrm{GP}^{+}$and typespecific HPV PCR analyses (17\%). Among the $27 \mathrm{hrHPV}^{+}$ lesions, 12 were both positive for $\mathrm{GP}^{+} / \mathrm{GP}^{+}$and type-specific $\mathrm{HPV}$ ( $\mathrm{hrHPV}^{+}$group), whereas 15 were negative for $\mathrm{GP}^{+} / \mathrm{GP}^{+}$ 


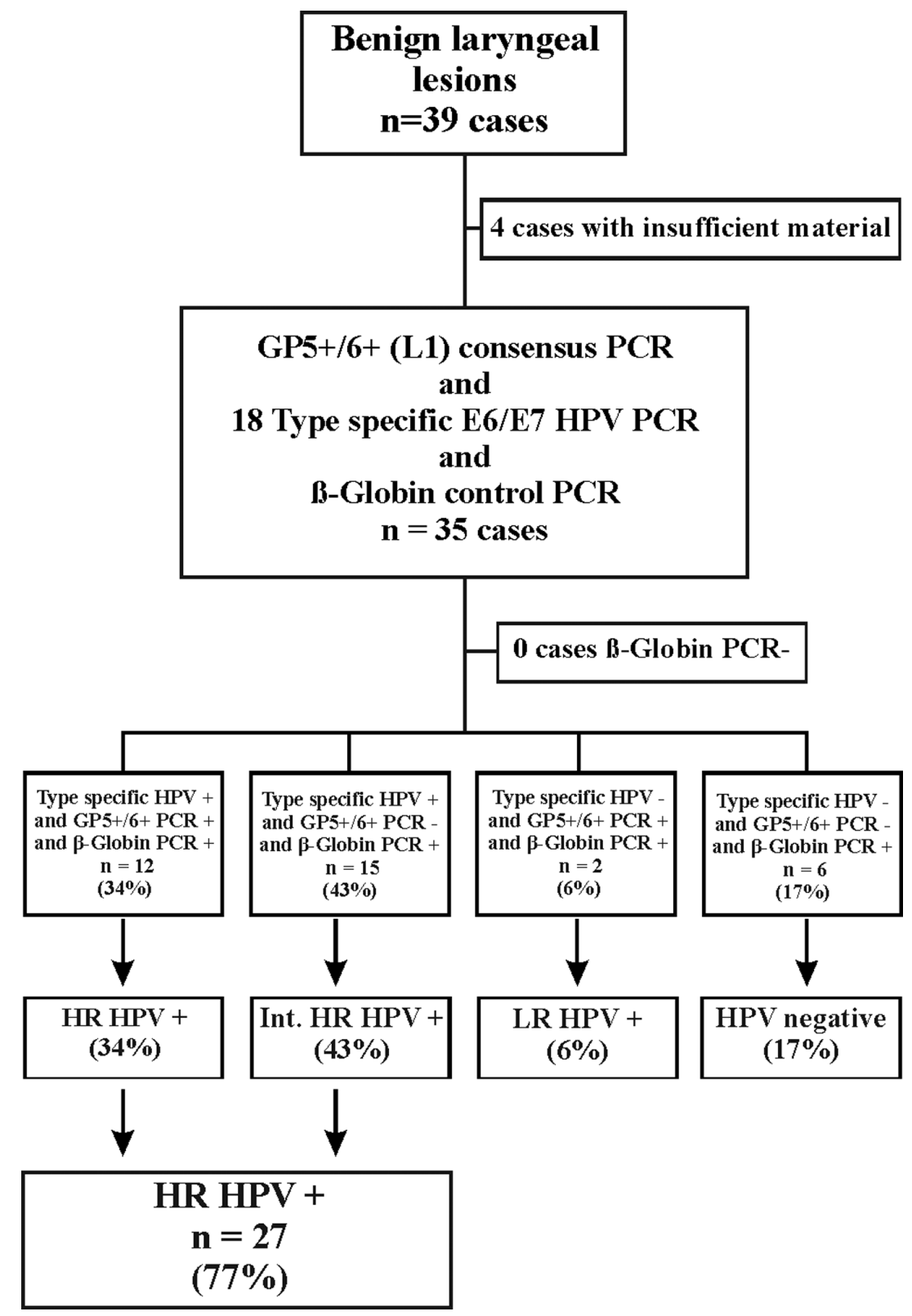

Figure 1. Flow diagram of the HPV PCR results from formalin-fixed, paraffin-embedded benign laryngeal lesion specimens included in this study. Archived tissue blocks were obtained from 39 patients with benign laryngeal lesions. These biopsies were collected from June 2001 to May 2009 . Four samples could not be analyzed due to insufficient material, and $\beta$-globin could be amplified from all other samples. Therefore, 35 cases were analyzed by type-specific real-time PCR and $\mathrm{GP}^{+} / \mathrm{GP}^{+}$consensus PCR. Among these patients, $77 \%$ tested positive for infection with one (type 16 ) or several types of hrHPV, 6\% were positive for $1 \mathrm{rHPV}$ and $17 \%$ were $\mathrm{HPV}$. Among the 27 patients with $\mathrm{hrHPV}^{+}$tumors, 12 tumors were both $\mathrm{GP}^{+} / \mathrm{GP}^{+}$-positive and type-specific $\mathrm{HPV}$-positive (hr-HPV ${ }^{+}$group); however, 15 tumors were $\mathrm{GP}^{+} / \mathrm{GP}^{+}-$-negative and type-specific $\mathrm{HPV}$-positive, which corresponds to the integrated $\mathrm{HPV}^{+}$group (int. hrHPV+).

and positive for type-specific HPV, which corresponds to the integrated $\mathrm{HPV}^{+}$group (int. hrHPV+) (Fig. 1).

HPV status in laryngeal squamous cell carcinoma specimens. Six cases out of the 67 LSCC specimens had insufficient tissue quantities available for DNA extraction after pathological evaluation and therefore were excluded from further analyses (Fig. 2). Out of the remaining 61 cases, two other cases were also excluded because $\beta$-globin was not amplified from these samples. Ultimately, 59 specimens were tested with both quantitative real-time PCR with primers for 18 different HPV types and the $\mathrm{GP}^{+} / \mathrm{GP}^{+}$primers (Fig. 2). From this clinical series of 59 LSCC tumor specimens, we identified 44 patients
(75\%) with tumors that were positive for the following hrHPV types: HPV-16 (37 cases), -18 (10 cases), -33 (3 cases), -35 (1 case), -39 ( 1 case), -51 ( 5 cases) and -66 (3 cases). In 13 specimens, multiple hrHPVs were detected. In the hrHPV-negative subgroup $(\mathrm{n}=15)$, three tumors were positive for the $\mathrm{GP} 5^{+} / \mathrm{GP}^{+}$ consensus PCR and were considered to be infected with lrHPV (Fig. 2). Only 12 tumors were negative in both the GP5 ${ }^{+} / \mathrm{GP}^{+}$ and type-specific HPV PCR analyses (20\%). Among the 44 hrHPV ${ }^{+}$tumors, 23 were both $\mathrm{GP}^{+} / \mathrm{GP}^{+}$-positive and typespecific HPV-positive (hr-HPV ${ }^{+}$group); however, 21 tumors were $\mathrm{GP}^{+} / \mathrm{GP}^{+}$-negative and type-specific HPV-positive, which corresponds to the integrated $\mathrm{HPV}^{+}$group (int. hrHPV ${ }^{+}$) (Fig. 2). There were no significant differences between the 


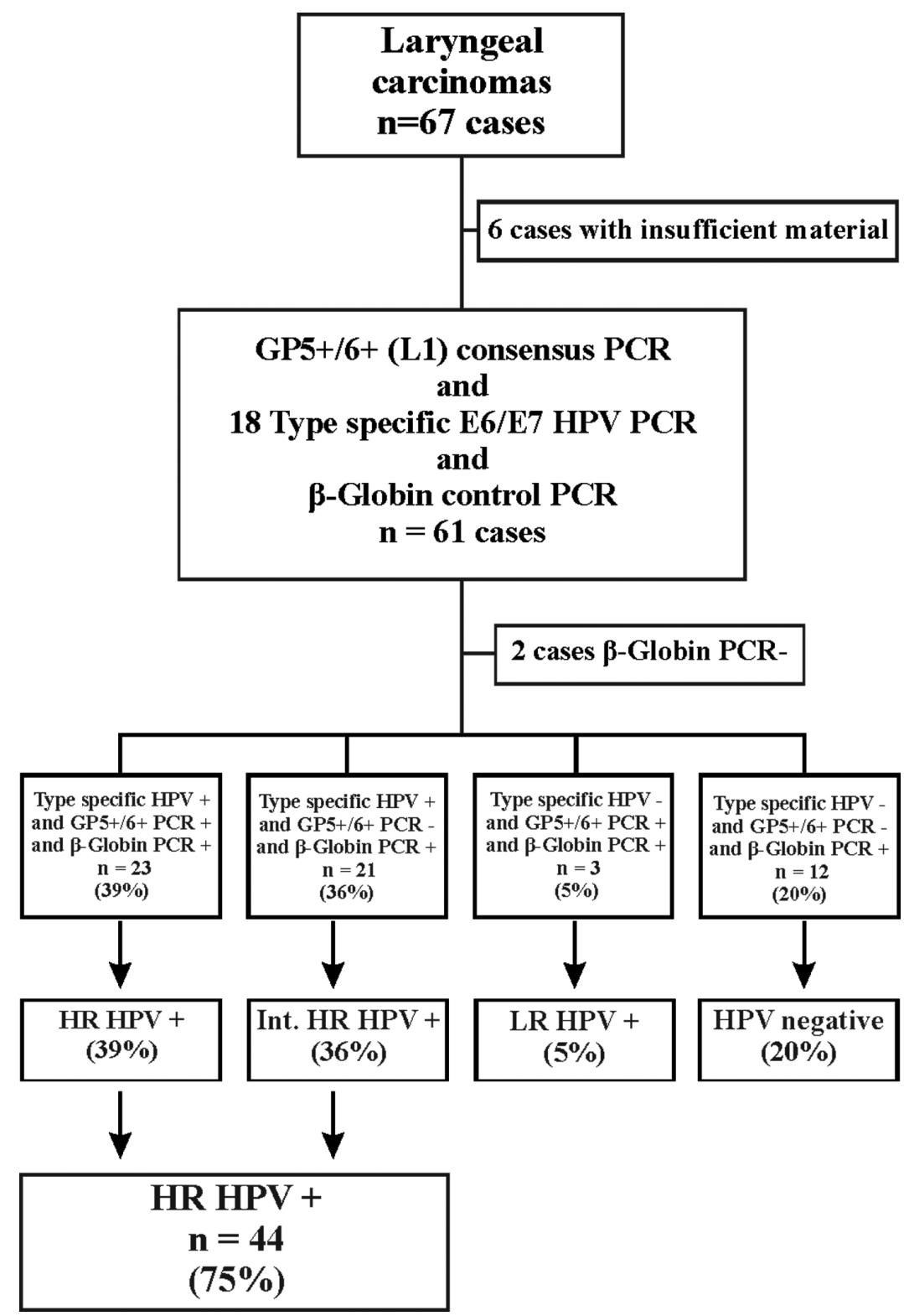

Figure 2. Flow diagram of the HPV PCR results from formalin-fixed, paraffin-embedded laryngeal carcinoma specimens included in this study. Archived tissue blocks were obtained from 67 patients who underwent curative surgery for laryngeal carcinoma between 2000 and 2007 . Six samples could not be analyzed due to insufficient material, and for two other samples, $\beta$-globin could not be amplified. Therefore, 61 cases were analyzed by type-specific real-time $\mathrm{PCR}$ and $\mathrm{GP}^{+} / \mathrm{GP}^{+}$consensus PCR. Among these patients, $75 \%$ tested positive for infection with one or several types of hrHPV, $5 \%$ were positive for $1 \mathrm{rHPV}$ and $20 \%$ were $\mathrm{HPV}$. Among the 44 patients with $\mathrm{hrHPV}^{+}$tumors, 23 tumors were both $\mathrm{GP}^{+} / \mathrm{GP6}^{+}$-positive and type-specific $\mathrm{HPV}^{-p o s i t i v e ~(h r-H P V}{ }^{+}$group); however, 21 tumors were $\mathrm{GP}^{+} / \mathrm{GP}^{+}$-negative and type-specific $\mathrm{HPV}$-positive, which corresponds to the integrated $\mathrm{HPV}^{+}$group (int. hrHPV $\mathrm{hl}^{+}$.

$\mathrm{HPV}^{+}$and $\mathrm{HPV}^{-}$subgroups regarding tobacco use, age, stage and differentiation.

Prognostic value of the presence of hr-HPV DNA in our series of laryngeal carcinomas. Positive hrHPV status did not correlate with the proportion of disease-free patients in our series of 59 patients (Fig. 3). The 5-year disease-free survival was $87 \%$ in $\mathrm{HPV}^{-}$or $1 \mathrm{rHPV}^{+}$low-stage tumors versus $76 \%$ in $\mathrm{hrHPV}^{+}$ low-stage tumors (log-rank test, not significant: NS) (Fig. 3A). The 5-year disease-free survival was $60 \%$ in $\mathrm{HPV}^{-}$or $1 \mathrm{rHPV}^{+}$ high-stage tumors versus $58 \%$ in $\mathrm{hrHPV}^{+}$high-stage tumors (log-rank test, NS) (Fig. 3B). After grouping the low and high stages, the 5-year disease-free survival was $77 \%$ in $\mathrm{HPV}^{-}$or $\mathrm{lrHPV}^{+}$laryngeal tumors versus $67 \%$ in $\mathrm{hrHPV}^{+}$laryngeal tumors (log-rank test, NS) (Fig. 3C).
Comparison of the HPV-16 viral loads in benign and malignant laryngeal lesions. Using quantitative PCR, we compared the HPV-16 viral loads in LBLs and LSCCs. This comparison showed that LSCCs had higher HPV-16 viral loads (median: 504 copies/specimen) than LBLs (median: 37 copies/specimen) (Fig. 4A, Mann-Whitney U test, $\mathrm{p}<10^{-6}$ ). A similar comparison between low- (median: 504 copies) and high-stage LSCCs (median: 780 copies) did not reveal any statistically significant difference in viral load (Fig. 4B, Mann-Whitney U test, not significant).

EGFR expression as determined by immunohistochemistry. Fig. 5A shows that typical EGFR immunostaining was located on the tumoral cell membrane. Of our LSCC specimens, 96\% were $\mathrm{EGFR}^{+}$. We analyzed EGFR expression in relation to 

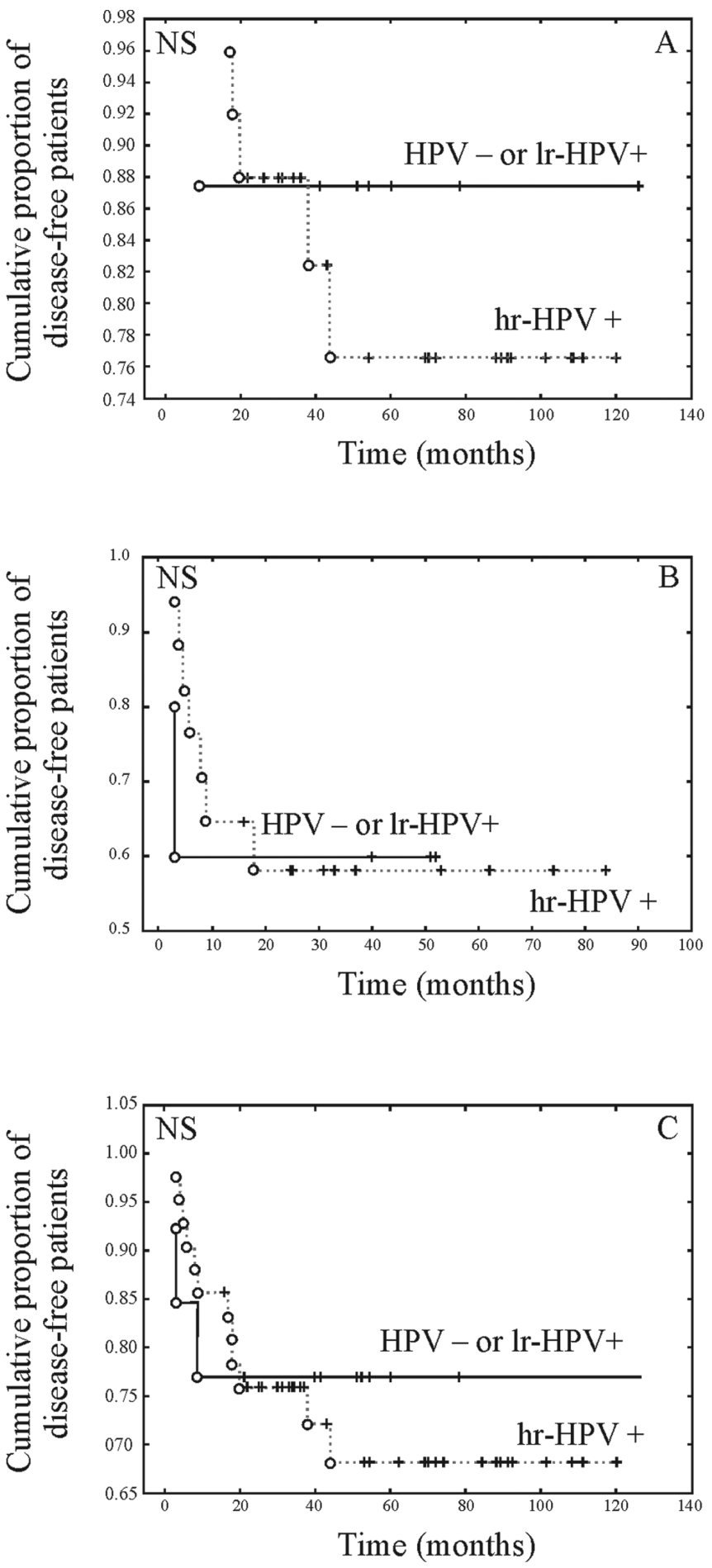

Figure 3. Disease-free survival curves for high-risk $\mathrm{HPV}^{+}\left(\mathrm{hrHPV}^{+}\right)$versus $\mathrm{HPV}^{-}$and low-risk $\mathrm{HPV}^{+}\left(1 \mathrm{rHPV}^{+}\right)$patients with low- (A) and high-stage (B) laryngeal carcinoma. (C) Disease-free survival curves for all stages together. The p-values were not significant (NS).

HPV status, and no statistically significant difference was observed between the HPV- and $1 \mathrm{r}-\mathrm{HPV}^{+}$subpopulations because both expressed EGFR in $100 \%$ of the specimens, and the $\mathrm{hr}-\mathrm{HPV}^{+}$carcinoma subpopulation was $\mathrm{EGFR}^{+}$in $97 \%$ of cases. Comparison of the disease-free survival curves based on the EGFR immunohistochemical staining did not show any statistically significant differences (Fig. 5B).
A

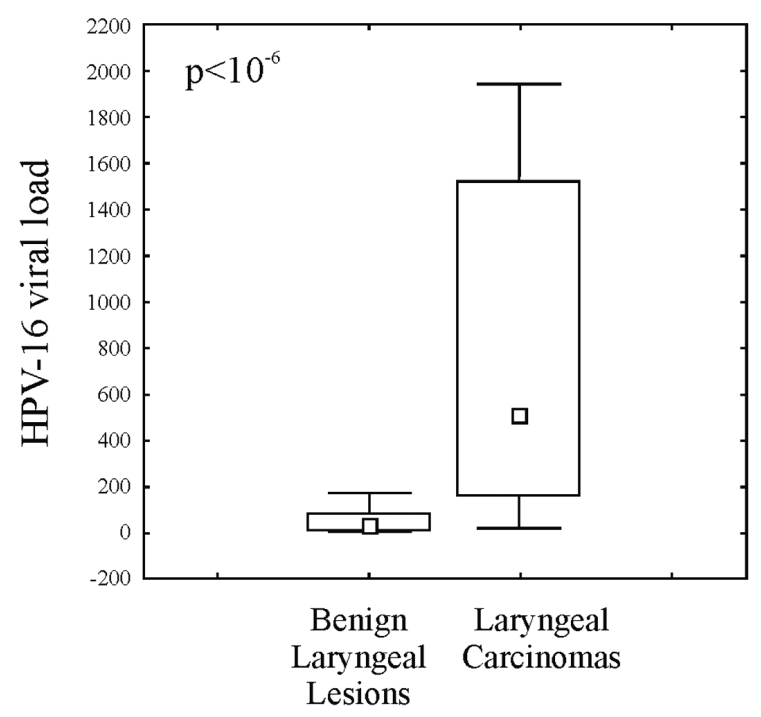

B

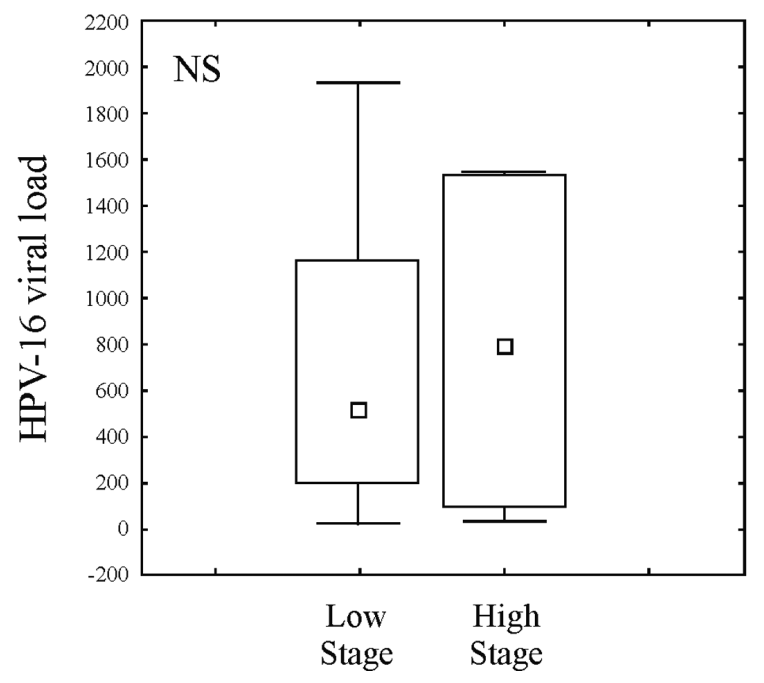

Figure 4. Mann-Whitney U test comparing the HPV-16 viral loads between LBLs and LSCCs (A) and between low- and high-risk carcinomas (B).

p16 expression as determined by immunohistochemistry. Expression of p16 was detected by immunohistochemistry in 97\% of LSCCs. As shown in Fig. 5C, the p16 immunostaining was nucleocytoplasmic. LSCC patients with higher p16 expression had the lowest rate of local recurrence (20\% recurrence 5 years after diagnosis) (Fig. 5C and D); however, there was no statistically significant differences between the four disease-free survival curves based on p16 immunohistochemical staining (Fig. 5D). All hrHPV tumors expressed p16.

p53 expression as determined by immunohistochemistry. Nuclear immunostaining of p53 was detected in 53\% of our LSCC specimens (Fig. 5E and F). The percentage of $\mathrm{p} 53^{+}$ LSCCs was comparable in both populations. Sixty-six percent of the HPV $/ 1 \mathrm{r}-\mathrm{HPV}^{+} \mathrm{LSCC}$ were $\mathrm{p}^{+} 3^{+}$. This percentage decreased to $56 \%$ in the hr-HPV ${ }^{+}$LSCC subpopulation. p53 

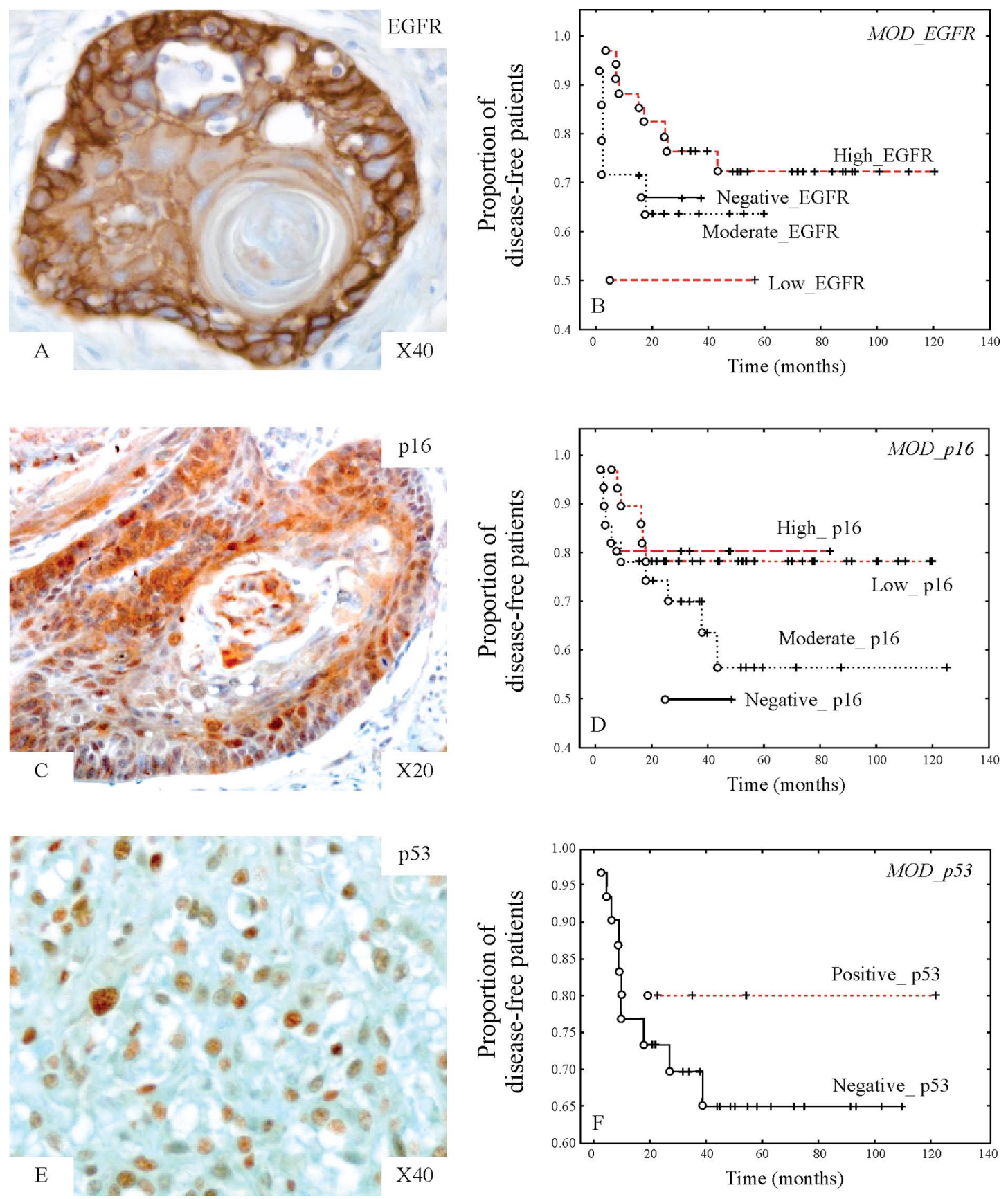

Figure 5. Typical EGFR, p16 and p53 immunohistochemical staining profiles for LSCCs (A, C and E). B, D and F show the survival curves of patients that express EGFR, p16 and p53 versus patients who do not express these three proteins.

overexpression did not correlate with the proportion of diseasefree patients in our series of LSCCs.

\section{Discussion}

Oncogenic human papillomaviruses (HPVs) have been proposed to be potential pathogenic factors in SCCs of the larynx. Studies dedicated to HPV infections in LSCCs have reported wide variations in frequency that range from 3 to $85 \%$ $(2,4-10)$. LSCCs are infected with a spectrum of oncogenic and non-oncogenic HPV types. This huge variation in HPV prevalence in LSCCs could be due to technical and geographical factors. In fact, these studies were mainly performed in North America and Europe, and PCR was used for viral detection.
After 20 years of HPV research, many assays for HPV DNA detection are available, and each has limitations. Recent PCR-based assay systems, such as the quantitative type-specific methods, have very high sensitivities, whereas the $\mathrm{GP}^{+} / \mathrm{GP}^{+}$ PCR is less sensitive for HPV detection (24). Our results confirmed this difference in sensitivity, but the combination of both PCR techniques allowed us to detect integrated HPV types because the $\mathrm{GP}^{+} / \mathrm{GP}^{+} \mathrm{PCR}$ detects the $\mathrm{L} 1$ region that is lost during integration, whereas the type-specific qPCR detects the E6/E7 regions. Therefore, the $\mathrm{GP} 5^{+} / \mathrm{GP}^{+}$-negative and type-specific HPV-positive cases correspond to the integrated $\mathrm{HPV}^{+}$group (int. hrHPV'). Our results showed a high prevalence of hrHPV infection (i.e., 75\%) in LSCCs. This is comparable to a previous study that showed a high 
incidence of HPV infection in LSCCs (2). The multiplex qPCR used in this study was recently validated on a large series of 10,000 liquid cervical cell samples from female residents of Flanders (24). The frequency of hrHPV infection was $11 \%$ in women without cytological abnormalities, and the prevalence of hrHPV infection was the highest in 20-24-year-old women (29\%) and decreased progressively with age (24). Moreover, we studied the incidence of HPV infections in a series of 80 patients undergoing tonsillectomies for hypertrophy, recurrent tonsillitis or snoring (unpublished data). These non-cancerous palatine tonsils showed a $28 \%$ incidence of HPV infection (unpublished data). This lower incidence in non-cancerous tonsils argues that the higher incidence in LSCCs is not due to contamination. Using the same qPCR methods in a series of 70 parotid tumors, only one case was $\mathrm{HPV}^{+}$. To prevent false-positives, precautions were taken to prevent tissue contamination. We recently showed that $82 \%$ of hypopharyngeal carcinomas were infected by hrHPV (18). Our results could be explained by the fact that we used a very sensitive (10-100 copies per PCR reaction) and type-specific real-time quantitative PCR analysis with a short amplification product (60-80 bp), which is less sensitive to the presence of degraded DNA in paraffin-embedded specimens. In a recent review dedicated to the molecular detection methods of HPV, Zaravinos and co-authors defined the PCR-based detection as a highly sensitive and specific method (26).

In our population of patients with LSCCs, there were no significant differences between the $\mathrm{HPV}^{+}$and $\mathrm{HPV}^{-}$subgroups regarding tobacco use, age, stage, differentiation and clinical outcomes (recurrence and survival). Importantly, our clinical series was composed of patients with very long-term follow-up times (ranging from 2 to 130 months), which is crucial for assessing the prognostic implications of HPV infections. Although there is strong support in the literature for the association between $\mathrm{HPV}^{+}$tumors and better prognoses, especially in oropharyngeal carcinomas, other studies did not find an improved prognosis for HPV-associated tumors $(18,27-30)$. On the other hand, Rosenquist et al (31) showed that among patients with oral and oropharyngeal tumors, the $\mathrm{hrHPV}^{+}$subgroup had a higher risk of recurrence or development of a second primary tumor but had a lower risk of death due to an intercurrent disease, compared to the hrHPV group. The significance of hrHPV infection and its relationship with LSCC prognosis is still an important matter of debate.

hr-HPVs produce two oncoproteins, which are encoded by the E6 and E7 genes, that are responsible for the abrogation of important cellular processes, such as cell cycle control and apoptosis (16). The main function of E6 is to bind to the tumor suppressor gene product p53, while E7 binds to the phosphorylated retinoblastoma tumor suppressor gene product $\mathrm{pRb}$ (16). After hrHPV integration, abnormal expression of E6 and E7 in the squamous epithelium has been proposed to initiate tumor progression. The p16 tumor suppressor gene is also frequently upregulated in $\mathrm{HPV}^{+} \mathrm{HNSCCs}$ because it is negatively regulated by $\mathrm{pRb}(32,33)$. Begum and colleagues (34) showed that p16 overexpression acts as a surrogate for $\mathrm{HPV}^{+}$oropharyngeal SCCs in lymph node metastases of oropharyngeal carcinomas. On the other hand, loss of p16 protein expression is a common and early event in tobaccorelated HNSCCs (33). Our results demonstrate that the biology of laryngeal SCCs is probably more complex than previously thought and that tumorigenesis probably involves several different molecular pathways, including the tobacco-related pathway and the HPV-related pathway. Our clinical series was composed of tobacco-associated carcinomas, and $75 \%$ of these specimens were $\mathrm{HPV}^{+}$. These results confirm our previous findings with a clinical series of 75 stage IV hypopharyngeal carcinomas, in which $82 \%$ of tobacco/alcohol-associated carcinomas were $\mathrm{HPV}^{+}(18)$. Moreover, we did not find any statistically significant differences between p16, p53 and EGFR immunohistochemical staining in $\mathrm{HPV}^{+}$and $\mathrm{HPV}^{-}$ laryngeal carcinomas.

Our results strongly support the proposition that a higher HPV-16 load in LSCCs (viral load median: 504 copies) is indicative of an active HPV infection, compared to our series of benign laryngeal lesions (median: 37 copies). This finding clearly shows that tobacco-related carcinomas are associated with active HPV-16 infections unlike benign laryngeal lesions. In fact, Cohen and colleagues demonstrated that $\mathrm{HPV}^{+}$tonsillar carcinomas that present a high HPV copy number are associated with a better prognosis than HPV- carcinomas (35). In our laryngeal series, stage IV carcinomas presented a higher HPV-16 copy number than stage I or II carcinomas; however, we did not find any statistically significant difference between HPV $-16^{+}$carcinomas with high copy numbers compared to those with low copy numbers.

Our results suggest that active HPV infections play a role in laryngeal carcinogenesis. The biology of tobacco-associated carcinomas is more complex than exclusively HPV-related carcinomas because we did not find any particular HPV biological signature using additional markers, including p16, p53 and EGFR. The question remains open as to whether there is any direct link between HPV infection and laryngeal cancers that could necessitate HPV vaccination in boys and girls (36). Prospective studies with large numbers of patients and controls are therefore required to confirm this hypothesis.

\section{Acknowledgements}

C.D. and P.D.. are Senior Research Associates of the Belgian National Fund for Scientific Research (FNRS, Brussels, Belgium); P.E.N and A.D. are Ph.D. students supported by a grant from the FNRS (Bourse Télévie).

\section{References}

1. Kreimer AR, Clifford GM, Boyle P and Franceschi S: Human papillomavirus types in head and neck squamous cell carcinomas worldwide: a systematic review. Cancer Epidemiol Biomarkers Prev 14: 467-475, 2005.

2. Aaltonen L-M, Rihkanen $\mathrm{H}$ and Vaheri A: Human papillomavirus in larynx. Laryngoscope 112: 700-707, 2002.

3. Gissmann L, Wolnik L, Ikenberg H, Koldovsky U, Schnürch HG and zur Hausen H: Human papillomavirus types 6 and 11 DNA sequences in genital and laryngeal papillomas and in some cervical cancers. Proc Natl Acad Sci USA 80: 560-563, 1983.

4. Almadori G, Cadoni G, Cattani P, et al: Detection of human papillomavirus DNA in laryngeal squamous cell carcinoma by polymerase chain reaction. Eur J Cancer 32: 783-788, 1996.

5. Boscolo-Rizzo P, Da Mosto MC, Fuson R, Frayle-Salamanca H, Trevisan R and Del Mistro A: HPV-16 E6 L83V variant in squamous cell carcinomas of the upper aerodigestive tract. J Cancer Res Clin Oncol 135: 559-566, 2009. 
6. Gallo A, Degener AM, Pagliuca G, Pierangeli A, Bizzoni F, Greco A and De Vincentiis M: Detection of human papillomavirus and adenovirus in benign and malignant lesions of the larynx. Otolaryngol Head Neck Surg 141: 276-281, 2009.

7. García-Milián R, Hernández H, Panadé L, et al: Detection and typing of human papillomavirus DNA in benign and malignant tumours of laryngeal epithelium. Acta Otolaryngol 118: 754-758, 1998.

8. Koskinen WJ, Brøndbo K, Mellin Dahlstrand H, et al: Alcohol, smoking and human papillomavirus in laryngeal carcinoma: a Nordic prospective multicenter study. J Cancer Res Clin Oncol 133: 673-678, 2007.

9. Lindeberg $\mathrm{H}$ and Krogdahl A: Laryngeal cancer and human papillomavirus: HPV is absent in the majority of laryngeal carcinomas. Cancer Lett 146: 9-13, 1999.

10. Rees L, Birchall M, Bailey M and Thomas S: A systematic review of case-control studies of human papillomavirus infection in laryngeal squamous cell carcinoma. Clin Otolaryngol Allied Sci 29: 301-306, 2004.

11. Nunez DA, Astley SM, Lewis FA and Wells M: Human papilloma viruses: a study of their prevalence in the normal larynx. J Laryngol Otol 108: 319-320, 1994.

12. Mammas IN, Sourvinos G, Vakonaki E, Giamarelou P, Michael C and Spandidos DA: Novel human papilloma virus (HPV) genotypes in children with recurrent respiratory papillomatosis. Eur J Pediatr 169: 1017-1021, 2010.

13. Steinberg BM, Topp WC, Schneider PS and Abramson AL: Laryngeal papillomavirus infection during clinical remission. $\mathrm{N}$ Engl J Med 308: 1261-1264, 1983

14. Doyle DJ, Henderson LA, LeJeune FE Jr and Miller RH: Changes in human papillomavirus typing of recurrent respiratory papillomatosis progressing to malignant neoplasm. Arch Otolaryngol Head Neck Surg 120: 1273-1276, 1994.

15. Spandidos DA: Oncogenes and tumor suppressor genes as paradigms in oncogenesis. J BUON 12: S9-S12, 2007.

16. Neufcoeur PE, Arafa M, Delvenne P and Saussez S: Involvement of human papillomavirus in upper aero-digestive tracts cancers Bull Cancer 96: 941-950, 2009.

17. Almadori G, Cadoni G, Cattani P, et al: Human papillomavirus infection and epidermal growth factor receptor expression in primary laryngeal squamous cell carcinoma. Clin Cancer Res 7 3988-3993, 2001.

18. Ernoux-Neufcoeur P, Arafa M, Decaestecker C, et al: Combined analysis of HPV DNA, p16, p21 and p53 to predict prognosis in patients with stage IV hypopharyngeal carcinoma. J Cancer Res Clin Oncol 137: 173-181, 2010.

19. Pim D, Collins M and Banks L: Human papillomavirus type 16 E5 gene stimulates the transforming activity of the epidermal growth factor receptor. Oncogene 7: 27-32, 2002.

20. Wittekind C, Greene FL, Hutter RVP, Klimpfinger $M$ and Sobin LH: TNM Atlas. In: International Union Against Cancer (UICC). 6th edition. Berlin, 2004

21. Hyams VJ, Batsakis JG and Michaels L (eds): Tumors of the upper respiratory tract and ear. In: Atlas of Tumor Pathology. Armed Forces Institute of Pathology, Washington, DC, 1988.

22. Depuydt CE, Benoy IH, Bailleul EJ, Vandepitte J, Vereecken AJ and Bogers JJ: Improved endocervical sampling and HPV viral load detection by Cervex-Brush Combi. Cytopathology 17: 374-381, 2006
23. Depuydt CE, Boulet GA, Horvath CA, Benoy IH, Vereecken AJ and Bogers JJ: Comparison of MY09/11 consensus PCR and type-specific PCRs in the detection of oncogenic HPV types. J Cell Mol Med 11: 881-891, 2007.

24. Arbyn M, Benoy I, Simoens C, Bogers J, Beutels B and Depuydt C: Prevaccination distribution of human papillomavirus types in women attending at cervical cancer screening in Belgium. Cancer Epidemiol Biomarkers Prev 18: 321-330, 2009.

25. Saussez S, Decaestecker C, Lorfevre F, et al: Increased expression and altered intracellular distribution of adhesion/growth-regulatory lectins galectins- 1 and -7 during tumour progression in hypopharyngeal and laryngeal squamous cell carcinomas. Histopathology 52: 483-493, 2008

26. Zaravinos A, Mammas IN, Sourvinos G and Spandidos DA: Molecular detection methods of human papillomavirus (HPV). Int H Biol Markers 24: 215-222, 2009.

27. Clayman GL, Stewart MG, Weber RS, el-Naggar AK and Grimm EA: Human papillomavirus in laryngeal and hypopharyngeal carcinomas. Relationship to survival. Arch Otolaryngol Head Neck Surg 120: 743-748, 1994.

28. Dahlstrand H, Näsman A, Romanitan M, Lindquist D, Ramqvist T and Dalianis T: Human papillomavirus accounts both for increased incidence and better prognosis in tonsillar cancer. Anticancer Res 28: 1133-1138, 2008

29. D'Souza G, Kreimer AR, Viscidi R, et al: Case-control study of human papillomavirus and oropharyngeal cancer. N Engl J Med 356: 1944-1956, 2007.

30. Kumar B, Cordell KG, Lee JS, et al: Response to therapy and outcomes in oropharyngeal cancer are associated with biomarkers including human papillomavirus, epidermal growth factor receptor, gender and smoking. Int J Radiat Oncol Biol Phys 69: 109-111, 2007.

31. Rosenquist K, Wennerberg J, Annertz K, Schildt EB, Hansson BG, Bladström A and Andersson G: Recurrence in patients with oral and oropharyngeal squamous cell carcinoma: human papillomavirus and other risk factors. Acta Otolaryngol 127: 980-987, 2007.

32. Hara E, Smith R, Parry D, Tahara H, Stone S and Peters G: Regulation of $\mathrm{p} 16^{\mathrm{CDKN} 2}$ expression and its implications for cell immortalization and senescence. Mol Cell Biol 16: 859-867, 1996.

33. Psyrri A and Di Maio D: Human papillomavirus and head and neck cancer. Nat Clin Pract Oncol 5: 24-31, 2008.

34. Begum S, Gillison ML, Ansari-Lari MA, Shah K and Westra WH: Detection for papillomavirus in cervical lymph nodes: a highly effective strategy for localizing site of tumor origin. Clin Cancer Res 9: 6469-6475, 2003.

35. Cohen MA, Basha SR, Reichenbach DK, Robertson E and Sewell DA: Increased viral load correlates with improved survival in HPV-16-associated tonsil carcinoma patients. Acta Otolaryngol 128: 583-589, 2008.

36. Mammas IN, Sourvinos G, Zaravinos A and Spandidos DA: Vaccination against human papilloma virus (HPV): epidemiological evidence of HPV in non-genital cancers. Pathol Oncol Res (In press). 